\title{
If you don't take it - it can't work: the consequences of not being treated or nonadherence to osteoporosis therapy
}

REVIEW

This article was published in the following Dove Press journal:

Therapeutics and Clinical Risk Management

24 May 2011

Number of times this article has been viewed

\author{
Jonathan D Adachi' \\ Robert G Josse ${ }^{2}$ \\ R Graham G Russell ${ }^{3,4}$ \\ 'Division of Rheumatology, \\ Department of Medicine, McMaster \\ University, Hamilton, Ontario, Canada; \\ ${ }^{2}$ Osteoporosis Center, Division \\ of Endocrinology and Metabolism \\ St. Michael's Hospital, University \\ of Toronto, Toronto, Ontario, \\ Canada; ${ }^{3}$ Nuffield Department of \\ Orthopaedics, Rheumatology and \\ Musculoskeletal Science, Oxford \\ University Institute of Musculoskeletal \\ Sciences (The Botnar Research \\ Centre), Nuffield Orthopaedic Center, \\ Oxford, UK; ${ }^{4}$ The Mellanby Center \\ For Bone Research, Department of \\ Human Metabolism, The University of \\ Sheffield Medical School, Sheffield, UK
}

Correspondence: Jonathan D Adachi Division of Rheumatology, Department of Medicine, McMaster University, 25 Charlton Avenue E, Suite 50I, Hamilton, Ontario,

Canada, L8N IY2

$\mathrm{Tel}+\mid$ 905-529-1317

Fax + | 905-52 I- 297

Email jd.adachi@sympatico.ca

\begin{abstract}
Osteoporosis is a growing problem worldwide, linked to an increasingly aging population. Despite the availability of a wide variety of treatments for osteoporosis, a significant number of patients are either not being prescribed treatment or discontinue therapy as early as 6 months after initiation. The reasons for a lack of adherence are many but poor adherence increases the risk of fracture and, therefore, the disease burden to the patient and society. Results from large-scale, randomized clinical studies have shown that different osteoporosis treatments are efficacious in reducing the risk of fracture. Studies assessing the effects of discontinuing osteoporosis therapies show that some treatments appear to continue to protect patients from the risk of future fracture even when treatment is stopped. However, these trials involve patients who have been compliant with treatment for between 2 and 5 years, a situation not reflective of real-world clinical practice. In reality, patients who discontinue therapy within the first 6 months may never achieve the optimum protection from fracture regardless of which treatment they have been prescribed. Clinicians need to develop management strategies to enable patients to adhere to their treatment. This will ultimately result in better prevention of fracture and a lower burden of disease to society and patients.
\end{abstract}

Keywords: osteoporosis, adherence, treatment, persistence, compliance, fracture

\section{Introduction}

Osteoporosis is a growing problem worldwide, linked to an aging population. Currently, a number of options are available for the treatment of postmenopausal osteoporosis (PMO). These include oral and intravenous (IV) bisphosphonates, hormone replacement therapy (HRT), selective estrogen receptor modulators (SERMs), human parathyroid hormone (PTH) preparations, strontium ranelate, and denosumab, an inhibitor of RANKL (Receptor Activator of Nuclear Factor $\mathrm{kB}$ Ligand).

Despite the availability of a number of efficacious treatments for osteoporosis, the issues of how to achieve effective protection from future fracture are more complex than the availability of such treatments. Barriers to achieving maximum fracture protection include diagnosis, appropriate follow-up after fracture, and adherence of patients to prescribed treatments. Ultimately, patients who do not receive or adhere to treatment will be at risk for future fracture, something that carries a significant cost to the patient in terms of their quality of life, increased morbidity and even mortality following some fragility fractures. ${ }^{2}$ Nonadherence to treatment also increases a patient's utilization of healthcare resources, thereby incurring a financial cost to both patient and healthcare provider. Understanding the factors which contribute to treatment effectiveness in clinical practice is, therefore, essential in order to minimize the disease burden. The aim of 
this review is to examine some of the barriers to diagnosis and patient adherence and to discuss the results from studies examining the consequences of discontinuing treatment.

\section{Barriers to treatment}

\section{Lack of diagnosis}

A significant barrier to achieving optimum fracture protection for an individual patient is the lack of a diagnosis of osteoporosis. Osteoporosis is often termed a 'silent disease' due to the lack of symptoms patients experience prior to the occurrence of a fracture. The presentation of a low-impact fracture should be a trigger to clinicians to assess fracture risk. However, a number of studies have indicated that this does not always happen. In a retrospective cohort study, 1162 women 55 years of age or older who had a distal radial fracture were identified from a claims database that includes more than 3 million patients in the USA, enrolled in multiple health plans. Of these women, only $33(2.8 \%)$ underwent a bone-density scan and 266 (22.9\%) were treated with at least one approved medication for the treatment of osteoporosis. This means that $67 \%$ of women in this study were not even assessed for their risk of fracturing. Overall, only 279 (24.0\%) of the women who sustained a distal radial fracture underwent either diagnostic evaluation or treatment of osteoporosis. ${ }^{3}$ The rate of diagnosis among men with a fragility fracture is even lower than for women. In a study of community-dwelling men aged 50 years and older, only $10.3 \%$ of men with a fragility fracture reported a diagnosis of osteoporosis within 5 years of the fracture event and less than $10 \%$ were receiving treatment. ${ }^{4}$ These data highlight a clear diagnostic and treatment care gap for patients with osteoporosis.

\section{Physician perception and recognition of osteoporosis}

Examination of how physicians view osteoporosis might provide some indication of why patients are not diagnosed and treated following a fracture. Orthopedic surgeons are often the first clinicians to see a patient with a fragility fracture and as such may be best placed to make an assessment of whether a patient has osteoporosis and requires treatment. A study of the attitudes of 107 orthopedic surgeons in the USA showed that $68 \%$ thought that the orthopedic surgeon should expand their practice to include the prescribing of pharmacological treatment for osteoporosis. Up to $70 \%$ of the respondents said they would favor a program in which they initiated medical treatment and/or full assessment of patients with an apparent osteoporotic fracture, provided that a primary care physician assumed the continuation of pharmacological management and the assessment of secondary causes of osteoporosis. Despite this, only $52 \%$ of respondents stated that they routinely notify the patient's primary care physician after seeing a patient with a probable osteoporotic fracture. This indicates that for some surgeons there is discordance between how they view their role in the identification of patients with osteoporosis and how they follow-up with primary care physicians. Most of the surgeons who responded to the survey (94\%) were concerned about the adverse events (AEs) associated with treatments for osteoporosis and $47 \%$ were concerned enough about AEs that they would rather avoid prescribing them altogether. ${ }^{5}$ The study did not examine whether there were specific AEs that prevented surgeons from wanting to prescribe osteoporosis treatments. This perception by clinicians regarding the safety of treatments for osteoporosis represents another potential barrier to treatment.

Within primary care, recognition of osteoporosis by physicians has proven to be low. For example, in a large survey of more than 85,000 Australian women aged 60 years and older who visited a primary care physician, approximately 57,000 reported symptoms and/or risk factors for osteoporosis. Of the 85,000 women who took part in the survey, $29 \%$ reported fractures. Despite this, only $8 \%$ of the women reporting symptoms and or/risk factors for osteoporosis had undergone bone mineral density (BMD) testing and only $25 \%$ of women reported a diagnosis of osteoporosis. ${ }^{6}$

\section{Rates of treatment with osteoporosis therapies}

Although there is still a gap in care between the number of patients who require treatment and the number who receive it, treatment with osteoporosis therapies was shown to have increased from 7\% to 31\% between 1995 and 2004, in patients who had experienced a hip fracture. ${ }^{7}$ During this period a number of bisphosphonates such as alendronate and risedronate were approved for use in the treatment of osteoporosis. Although the rates of prescribing of osteoporosis medications have increased over time, ${ }^{8}$ there is evidence that prescribing of bisphosphonates is currently not increasing or is even on the decline.

\section{The problem of noncompliance, nonpersistence and treatment discontinuation Compliance and persistence with osteoporosis treatments}

A lack of adherence (compliance and persistence) by patients to their treatment is an issue for most chronic 
diseases, including osteoporosis. Evidence for the efficacy of osteoporosis treatments comes from randomized, controlled clinical trials (RCTs) in which patients are carefully monitored and are in regular contact with healthcare professionals. ${ }^{9-16}$ This results in compliance and persistence rates of between $60 \%$ and $81 \% .^{11,16-18}$ However, in the realworld clinical practice setting, numerous studies have shown that compliance and persistence by patients to osteoporosis treatment is poor. ${ }^{19-26}$

Data from a study by Siris et al of more than 35,000 women who received a bisphosphonate prescription showed that $57 \%$ of those prescribed alendronate or risedronate (daily or weekly doses) were noncompliant and $80 \%$ were nonpersistent within 2 years of initiating treatment. ${ }^{25} \mathrm{In}$ this study, compliance was defined using the medication possession ratio (MPR), calculated as the sum of the days supply divided by the follow-up time. Patients were deemed compliant if their MPR was $\geq 0.80$. Persistence was defined as the length of time a patient received continuous therapy without a gap in refills $>30$ days. The study showed that noncompliance or nonpersistence with treatment led to a significant reduction in treatment benefit such that patients who only took half their medication over 2 years achieved no better efficacy than if they had never taken any medication. ${ }^{25}$ Another study by Downey et al used a managed care administration claims database from the USA to examine the adherence and persistence of 10,566 women, newly diagnosed with PMO to treatment with alendronate, risedronate or raloxifene. ${ }^{20}$ Adherence rates to treatment with both daily and weekly alendronate and risedronate were $60.7 \%$, and $58.4 \%$ respectively, and with raloxifene were $53.9 \%$. Persistence rates at 12 months were $21.3 \%$ for alendronate, $19.4 \%$ for risedronate and $16.2 \%$ for raloxifene. The study showed that persistence rapidly declined in the first 3 months of treatment, with a slower, more gradual decline over the following 9 months. The lack of persistence at 12 months was comparable in this study to that found by Siris et al at 2 years. ${ }^{25} \mathrm{~A}$ recent metaanalysis of 15 studies assessing adherence to osteoporosis treatment showed that the mean number of days patients persisted with alendronate, risedronate or ibandronate treatment ( $\mathrm{n}=236,540)$ was 184 (95\% CI 164-204). The mean MPR for patients treated with alendronate or risedronate $(\mathrm{n}=234,737)$ was $66.9 \%(95 \%$ CI $63-70) .{ }^{27}$ The results from this meta-analysis show that across multiple studies, patients are discontinuing their treatment within 6 months and that, even within this timeframe, they are not taking their medication on a regular basis.
A lack of persistence to treatment by a patient may also not be permanent or irreversible. A study of Australian veterans who were prescribed oral bisphosphonates following a fracture showed that although the majority of users $(68 \%)$ did not persist with treatment, $19 \%$ of users had two treatment episodes and 13\% had three or more episodes of use. In this study an episode of use was determined as the number of treatment days between the first prescription and the date of the last prescription plus 35 days. ${ }^{28}$ These data indicate that there may be opportunities for clinicians to restart their patients on treatment even when they have previously stopped taking it and that finding out the root causes of why a patient has desisted are important in increasing the length of time on treatment.

In addition, clinicians may also have a misconception of how adherent their patients are. In a survey of 412 clinicians, it was estimated that $69.2 \%$ of patients were adherent after 12 months of treatment. Pharmacy claims for the same patients showed that only $48.7 \%$ were adherent after 12 months. Clinicians' perceptions did not significantly differ according to medication class or frequency of administration..$^{29}$

\section{Reasons for lack of compliance and persistence with osteoporosis therapies}

Determining why patients are noncompliant and nonpersistent is important in enabling clinicians to select the most appropriate treatment. Numerous studies have examined the reasons why patients fail to comply with instructions on how to take their medication or stop taking their medication altogether. Common reasons for nonadherence include AEs, either real or perceived, complicated dosing regimens and a lack of knowledge surrounding osteoporosis and the importance of fracture prevention. ${ }^{30}$ AEs are an issue for all osteoporosis treatments, but events such as GI irritation, which may be associated with oral bisphosphonates, can often be made worse if patients do not take their medication according to the instructions (sufficient water, upright position and fasting state). ${ }^{31}$ Other reasons for a lack of adherence to treatment include the dosing intervals of different treatments. Studies which have examined the adherence of patients have shown that patients prefer and are more adherent to weekly versus daily alendronate ${ }^{32,33}$ and monthly versus weekly bisphosphonates..$^{34}$ However, even with weekly treatment, patients still had suboptimal adherence. ${ }^{35}$ The availability of intravenous (IV) bisphosphonates such as ibandronate (quarterly dosing) and zoledronic acid (annual dosing) may lead to improved adherence by patients. A preference study 
of patients recently diagnosed with osteoporosis showed that out of oral bisphosphonates (daily or weekly), IV bisphosphonates every 3 months, or IV bisphosphonates once-yearly, $65 \%$ of patients preferred annual over weekly dosing. ${ }^{36}$

Adherence may also be influenced by the use of generic versions of branded medication. A recent study by Ringe and Moller of the differences in patient persistence between generic and original branded once-weekly bisphosphonates, using the clinical records of 204 women, showed clear differences in the persistence rates between generic and branded oral bisphosphonates. ${ }^{33}$ At 12 months, 68\% of patients were still taking generic alendronate compared with $84 \%$ of patients taking branded alendronate $\left(\right.$ Fosamax $\left.^{\circledR}\right)$. The persistence rates for this study are much higher than has been seen in other clinical practice studies; ${ }^{19,20,25}$ however, it does suggest that patients are less likely to persist with generic alendronate compared with branded. Examination of the number of GI AEs experienced by patients in this study showed that significantly more patients taking generic alendronate experienced a GI AE than patients taking branded alendronate (32 patients versus 15 patients, respectively; $P<0.05) .{ }^{33}$ These data are further supported by a report showing that patients who were previously stable on doses of branded alendronate experienced an increase in AEs which resulted in treatment discontinuation after switching to a generic version of alendronate. ${ }^{37}$

Belief in the importance of taking medication for the treatment of osteoporosis and the relationship between the patient and healthcare provider are two important considerations when trying to achieve maximum adherence. ${ }^{30}$ Patients must understand the nature of the disease and how it progresses in order to compensate for the asymptomatic nature of osteoporosis. A close relationship between the healthcare provider and the patient has been shown to improve adherence by $57 \%$ among postmenopausal women with osteopenia. ${ }^{38}$

\section{Consequences of a lack of compliance and persistence with osteoporosis therapies}

A lack of adherence to osteoporosis treatment will ultimately have an effect on the degree of fracture protection patients might achieve. In a study of over 38,000 women with PMO who received a prescription for a bisphosphonate, low compliance (MPR $<80 \%$ ) was found to be associated with a $31 \%$ higher risk of fracture $(P<0.0001)$. Hospitalization rates were $47 \%$ higher in patients with poor compliance $(\mathrm{MPR}<50 \%)$ than in those patients with excellent compliance $(\mathrm{MPR}>90 \%){ }^{22}$ In a later study by Penning-van Beest et al of 8,822 female bisphosphonate users, a MPR of $<20 \%$ was associated with an $80 \%$ increased fracture risk compared with patients with a MPR of $\geq 90 \% .{ }^{39}$ Results from a meta-analysis of adherence to osteoporosis treatments by Danese et al showed that the risk of fracture was $46 \%$ greater for patients with poor compliance to bisphosphonates (MPR $<80 \%$ ) compared with highly compliant patients (MPR $\geq 80 \%$ ), over $1-2.5$ years. Examination of the fracture risk for different fracture sites showed that lack of compliance affected the risk of clinical vertebral fractures most (43\%), followed by hip (28\%) and nonvertebral fractures (16\%). ${ }^{40}$ These findings have clear implications for wasted healthcare expenditures on unused medication, and increased outlays for hospital and other direct and indirect medical costs. Danese et al have modeled the effect of adherence on lifetime fractures in osteoporotic women who receive treatment with oral bisphosphonates. ${ }^{40}$ They compared the benefits of patients being highly compliant with treatment, both in terms of fracture rates and monetary cost, with the current state of adherence with daily and weekly bisphosphonate therapies in the USA. Optimal adherence was defined as a MPR $>90 \%$. Using this model, the overall fracture rates per 1000 patient years for usual adherence were calculated to be 58 (95\% CI 51-64) compared with 44 (95\% CI 36-53) for optimal adherence. The increase in fracture costs between usual and optimal adherence was estimated to be USD $\$ 2100$ (95\% CI 400-7300) based on site-specific United States Department of Labor Consumer Price Index-based estimates for the 1-year direct medical cost of fracture. Despite the increase in fracture costs between usual and optimum adherence, the study showed that optimal adherence was more expensive overall, compared with usual adherence (USD \$1700 [95\% CI 4100 to -3300$])$. When this was examined further, the authors calculated that the increase in cost was due to the cost of medication (generic and branded). In this study, a number of assumptions were made in the process of assessing cost. For example, patients were assumed to be free of fracture at the time treatment was initiated and the cost of fracture after 1 year and the quality of life decrements associated with fracture were not incorporated. The authors also assumed that all patients with a $\mathrm{T}$ score $\leq-2.5$ were treated with bisphosphonates. It is clear that in clinical practice not all of these assumptions will be true, and so the estimates of the cost of adherence, both usual and optimum, should be interpreted with caution. ${ }^{40}$ 


\section{Consequences of discontinuing osteoporosis treatment}

The efficacy of different osteoporosis treatments has been demonstrated in a number of large-scale clinical trials (Tables 1-4). Follow-up studies have examined the clinical consequences of discontinuing treatment, information that is important given the previously discussed issues of poor persistence.

\section{HRT and SERMs}

In a study of older women aged 65-77 years who received 3 years of treatment with estrogen or placebo and 2 years of no further treatment, overall spine BMD was not significantly different to baseline at the end of 5 years. The lack of overall difference in BMD was the result of a loss of BMD during the 2 years of no treatment that counteracted the gains made during active treatment. ${ }^{41}$ The fall in BMD after discontinuation of estrogen was also accompanied by a rapid increase (rebound) back to baseline in the bone turnover marker (BTM) urinary crosslinked $\mathrm{N}$-telopeptide of type I collagen (urinary NTX), indicating a significant increase in bone remodeling in this population of women. ${ }^{41}$ Although this study has shown a rapid loss of BMD after discontinuation of treatment, a follow-up study ( 5,11 or 15 years) of healthy postmenopausal women who had received 2-3 years of treatment with HRT in their early postmenopausal years showed that despite a loss of BMD once treatment was stopped, patients previously treated with HRT had a significantly lower risk of vertebral fracture at the time of follow-up compared with women on placebo (odds ratio 0.47 [95\% CI 0.24-0.93]; $P=0.03$ ). The risk of nonvertebral fractures was $32 \%$ lower in patients treated with HRT, compared with patients in the placebo group, but did not reach statistical significance. ${ }^{42}$

Data from a study of postmenopausal women who were randomized to receive treatment with raloxifene $60 \mathrm{mg}$ or estrogen for 5 years showed that despite significant increases in lumbar spine BMD versus baseline $(P=0.024$ and $P=0.045$, respectively), within 1 year of discontinuation of treatment lumbar spine BMD was significantly lower compared with the end-of-treatment values $(P=0.001$ and $P=0.012$, respectively) (Figure 1A). A significant decline in femoral neck BMD was also observed after discontinuation of raloxifene treatment (Figure 2A). ${ }^{43}$

\section{Bisphosphonates}

\section{Alendronate}

In the FIT Long-term Extension (FLEX) follow-up study women who had received treatment with alendronate for 5 years during the FIT trial were re-randomized to receive alendronate 5 or $10 \mathrm{mg} /$ day or placebo for a further 5 years. ${ }^{44}$ Women randomized to placebo, and who therefore discontinued treatment with alendronate, showed a moderate decline in BMD at the total hip (-3.38\%), femoral neck $(-1.48 \%)$ (Figure 2B) and trochanter $(-3.25 \%)$ at the end of 5 years of placebo treatment, compared with the end of treatment with alendronate. In contrast, lumbar spine BMD increased for the same women during this period (Figure 1B). Mean levels of BTMs gradually increased in women who discontinued treatment with alendronate compared with women who continued taking alendronate. However, when compared with pretreatment levels in the FIT study 10 years previously, levels of serum C-telopeptide of type I collagen (CTX) (Figure 3A) and bone alkaline phosphatase (ALP) at the end of 5 years of placebo treatment had not returned to baseline pretreatment levels. ${ }^{44}$ Despite the changes in BMD and BTMs there were no significant differences in RR of all clinical fractures or nonvertebral fractures between women who continued with alendronate treatment and those who received placebo treatment over the 5-year follow-up. A significant difference in risk of clinical vertebral fractures was observed, with a RR of a clinical vertebral fracture of 0.45 (95\% CI $0.24-0.85)$ for women who continued with alendronate treatment versus those who switched to placebo. A post-hoc analysis of the data showed that in women who did not have a vertebral fracture at FLEX baseline, continuation of treatment with alendronate reduced nonvertebral fractures in women with FLEX baseline femoral neck T-scores $<-2.5$ (RR 0.50; 95\% CI $0.26-0.96$ ) but not with T-scores $>-2.5$ and $<-2$ (RR $0.79 ; 95 \%$ CI $0.37-1.66)$ or with T-scores $>-2$ (RR 1.41; 95\% CI 0.75-2.66) ( $\mathrm{p}$ for interaction $=0.019$ ). In the group of women with a vertebral fracture at baseline, there were no significant interactions between FLEX baseline femoral neck BMD and the effect of continued treatment with alendronate on any fracture outcomes, although the numbers of women who experienced a fracture were small. ${ }^{45}$ In patients who received placebo, neither prevalent vertebral fracture at baseline or femoral neck T-score had a significant interaction on the risk of nonvertebral or clinical vertebral fractures. However, data from this group were not analyzed using both parameters together. ${ }^{44}$ It should perhaps be noted that in this study, only $72 \%$ of patients were still taking their assigned medication at the end of the 5-year study. ${ }^{44}$

\section{Risedronate}

Follow-up assessment of 599 women with PMO who took part in the Vertebral Efficacy with Risedronate Therapy trials showed that 1 year after stopping treatment, lumbar spine 


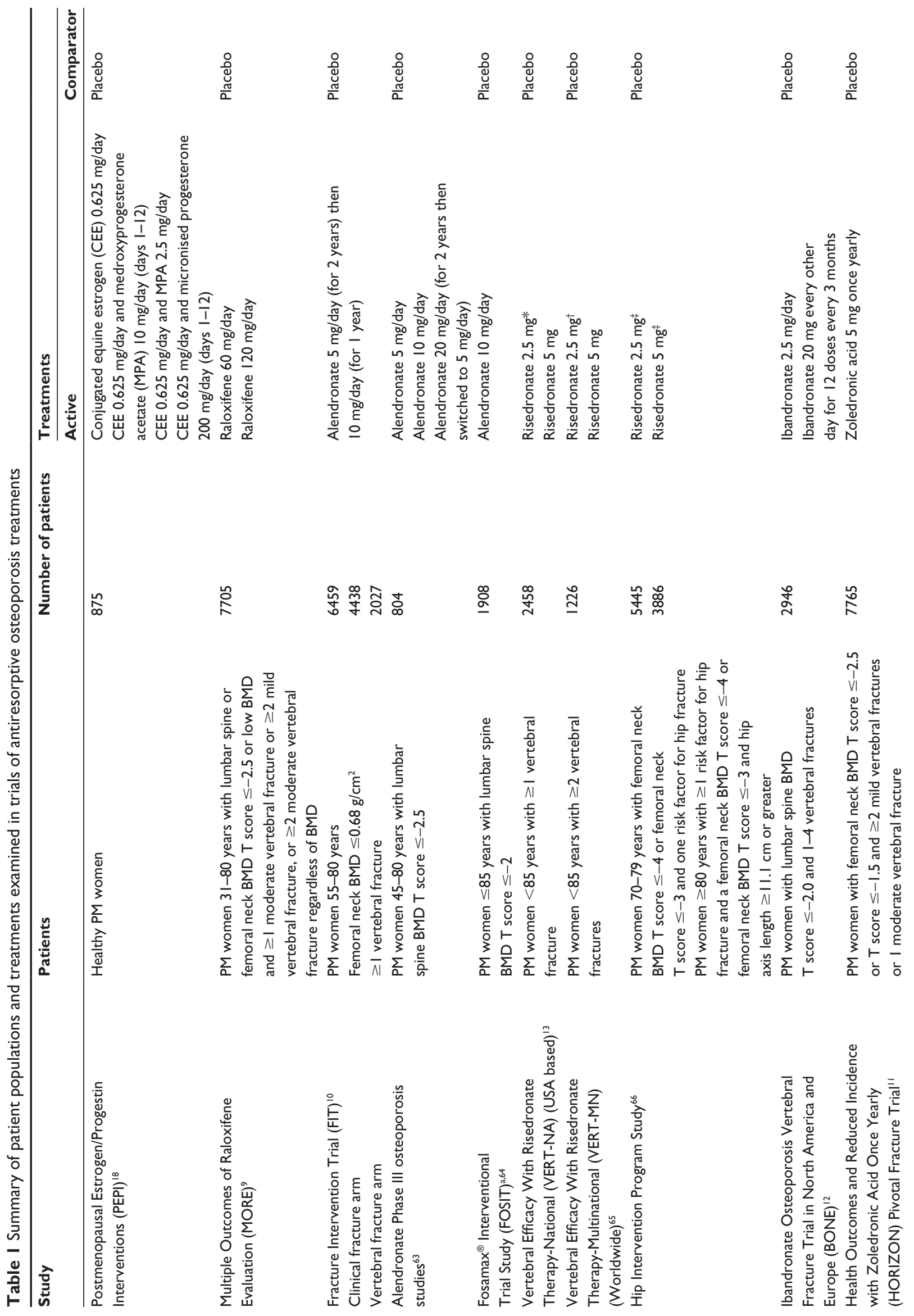




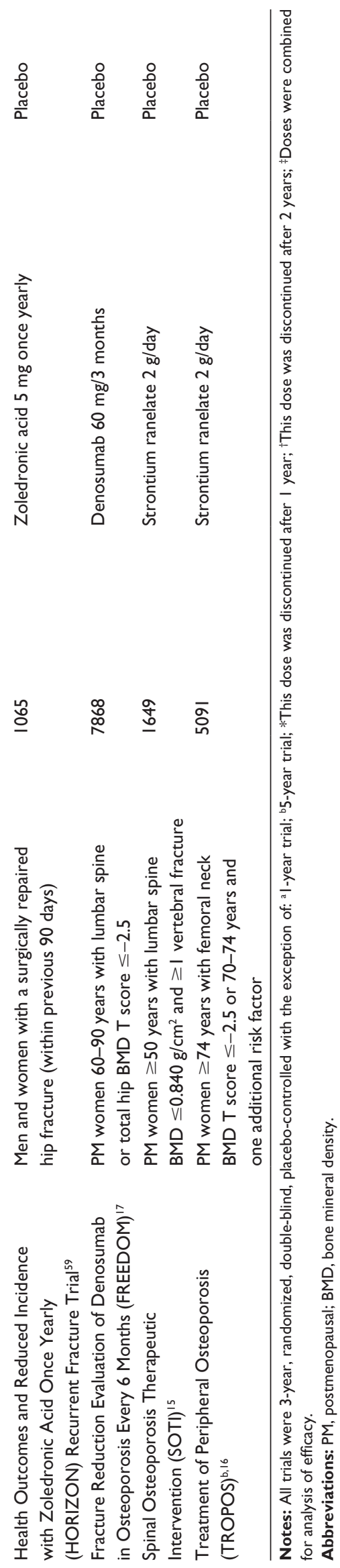

BMD had significantly decreased compared with placebo at the end of 3 years of treatment (Figure 1C). However, the decline was gradual and BMD remained significantly above baseline levels and above the lumbar spine BMD of the original placebo group. A significant decline in femoral neck BMD also occurred in the year after treatment was discontinued (Figure 2C). Levels of urinary NTX and bone ALP gradually rose following discontinuation, as with treatment with alendronate, levels did not return to baseline within the follow-up period (Figure 3B). Despite gradual but significant declines in BMD, there remained a significant reduction in risk of vertebral fractures in the former risedronate group compared with the placebo group, 1 year after treatment was stopped. ${ }^{46}$

\section{Ibandronate}

There is currently a lack of published information regarding the clinical consequences of discontinuing treatment with ibandronate.

\section{Zoledronic acid}

Devogelaer et al showed that in a Phase II, dose-ranging study of treatment with zoledronic acid $4 \mathrm{mg}$ over 5 years, women with PMO who received 3 years of treatment and were then followed up for 2 years showed an overall gain in BMD at the end of treatment which was maintained during the years without treatment. ${ }^{47}$ Lumbar spine BMD at 5 years had increased by $9.01 \%$ compared with baseline, proximal femur by $4.92 \%$, distal radius by $2.60 \%$ and total body by $3.59 \%$. Analysis of serum levels of CTX and bone ALP show that once treatment had been stopped, levels of both markers gradually rose but did not return to baseline during the follow-up period. Levels were also well within the normal range for the duration of the study and follow-up. ${ }^{47}$ Data from a 3-year extension to the HORIZON-PFT are expected shortly and should provide information about the effects of continuing versus discontinuing treatment with zoledronic acid.

\section{RANKL inhibitors \\ Denosumab}

Data on the effects of discontinuing treatment with denosumab are limited; however, in a Phase III trial, 332 postmenopausal women with low bone mass who received treatment with either denosumab $60 \mathrm{mg}$ or placebo every 6 months for 2 years showed a rapid decrease in lumbar spine and total hip BMD back to baseline within 12 months of discontinuing treatment. Total hip BMD continued to decrease over the next 12 months. ${ }^{48}$ Data on changes in BTMs for this study are currently unavailable. However, in a phase II study, 
Table 2 Summary of results from trials of antiresorptive osteoporosis treatments

\begin{tabular}{|c|c|c|c|}
\hline \multirow[t]{2}{*}{ Study } & \multirow[t]{2}{*}{ Treatments } & \multicolumn{2}{|c|}{$\begin{array}{l}\text { Fracture reduction versus placebo } \\
\text { over } 3 \text { years (RR }[95 \% \mathrm{CI}] \text { ) }\end{array}$} \\
\hline & & Vertebral & Nonvertebral \\
\hline Postmenopausal Estrogen/Progestin & Placebo & & \\
\hline \multirow[t]{8}{*}{ Interventions (PEPI) ${ }^{18}$} & Conjugated equine estrogen (CEE) & $N / R$ & $N / R$ \\
\hline & $0.625 \mathrm{mg} / \mathrm{day}$ & & \\
\hline & CEE $0.625 \mathrm{mg} /$ day and & & \\
\hline & medroxyprogesterone acetate & & \\
\hline & (MPA) 10 mg/day (days I-12) & & \\
\hline & CEE $0.625 \mathrm{mg} /$ day and MPA $2.5 \mathrm{mg} /$ day & & \\
\hline & CEE $0.625 \mathrm{mg} /$ day and micronised & & \\
\hline & progesterone $200 \mathrm{mg} /$ day (days I-I2) & & \\
\hline \multirow{4}{*}{$\begin{array}{l}\text { Multiple Outcomes of Raloxifene } \\
\text { Evaluation (MORE) }\end{array}$} & Placebo & & \\
\hline & & & \\
\hline & Raloxifene $60 \mathrm{mg} /$ day & $0.7(0.5-0.8)$ & $\begin{array}{l}\text { Raloxifene combined } \\
\text { group }=0.9(0.8-1.1)\end{array}$ \\
\hline & Raloxifene $120 \mathrm{mg} /$ day & $0.5(0.4-0.7)$ & $N / R$ \\
\hline Fracture Intervention Trial $(\mathrm{FIT})^{10}$ & Placebo & & \\
\hline Combined population & $\begin{array}{l}\text { Alendronate } 5 \mathrm{mg} / \text { day (for } 2 \text { years) then } 10 \mathrm{mg} / \text { day } \\
\text { (for I year) }\end{array}$ & $0.52(0.42-0.66), P<0.001$ & $\begin{array}{l}0.73(0.61-0.87) \\
P<0.001\end{array}$ \\
\hline Clinical & Placebo & & \\
\hline fracture $\operatorname{arm}^{67}$ & $\begin{array}{l}\text { Alendronate } 5 \mathrm{mg} / \text { day (for } 2 \text { years) then } 10 \mathrm{mg} / \text { day } \\
\text { (for } 2 \text { years) }^{\mathrm{a}}\end{array}$ & $0.56(0.39-0.80)$ & $0.88(0.74-1.04)$ \\
\hline Vertebral & Placebo & & \\
\hline fracture $\operatorname{arm}^{68}$ & $\begin{array}{l}\text { Alendronate } 5 \mathrm{mg} / \text { day (for } 2 \text { years) then } 10 \mathrm{mg} / \text { day } \\
\text { (for I year) }\end{array}$ & $0.45(0.27-0.72)$ & $0.80(0.63-1.01)$ \\
\hline Alendronate Phase III & Placebo & & \\
\hline \multirow[t]{3}{*}{ Osteoporosis Studies ${ }^{63}$} & Alendronate $5 \mathrm{mg} /$ day & $\begin{array}{l}\text { Pooled alendronate data }=0.52 \\
(0.28-0.95)\end{array}$ & $P=N S$ \\
\hline & Alendronate $10 \mathrm{mg} /$ day & $N / R$ & $N / R$ \\
\hline & $\begin{array}{l}\text { Alendronate } 20 \mathrm{mg} / \text { day (for } 2 \text { years then switched } \\
\text { to } 5 \mathrm{mg} / \text { day) }\end{array}$ & $N / R$ & $N / R$ \\
\hline Fosamax ${ }^{\circledR}$ Interventional & Placebo & & \\
\hline Trial Study (FOSIT) $)^{\mathrm{b}, 64}$ & Alendronate $10 \mathrm{mg} /$ day & $N / R$ & $\begin{array}{l}\text { After I year } \\
0.53(0.30-0.90)\end{array}$ \\
\hline Vertebral Efficacy With Risedronate & Placebo & & \\
\hline Therapy-National (VERT-NA) ${ }^{13}$ & Risedronate $5 \mathrm{mg}$ & $0.59(0.43-0.82), P=0.001$ & $\begin{array}{l}0.60(0.39-0.94) \\
P=0.02\end{array}$ \\
\hline Vertebral Efficacy With Risedronate & Placebo & & \\
\hline Therapy-Multinational (VERT-MN) ${ }^{69}$ & Risedronate $5 \mathrm{mg}$ & $0.5 \mathrm{I}(0.36-0.73), P<0.00 \mathrm{I}$ & $P=N S$ \\
\hline \multirow[t]{2}{*}{ Hip Intervention Program Study ${ }^{66}$} & Placebo & & \\
\hline & Risedronate $5 \mathrm{mg} *$ & $N / R$ & $N / R$ \\
\hline
\end{tabular}


Mean change from baseline over 3 years (percentage)

\begin{tabular}{lllll}
\hline Hip & Lumbar spine BMD & Femoral neck BMD & Serum CTX & Serum bone ALP \\
\hline \multirow{2}{*}{ N/R } & $-2.8 \%$ & $N / R$ & $N / R$ & $N / R$ \\
& All active & & $N / R$ & N/R
\end{tabular}

\begin{tabular}{|c|c|c|c|c|}
\hline & $N / R$ & $N / R$ & $\begin{array}{l}\text { Urinary CTX } \\
-8.1 \%\end{array}$ & $N / R$ \\
\hline$N / R$ & $\begin{array}{l}\text { Change versus placebo } \\
2.1 \%, P<0.001\end{array}$ & $\begin{array}{l}\text { Change versus placebo } \\
2.65, P<0.001\end{array}$ & $\begin{array}{l}\text { Urinary } C T X \\
-34.0 \%, P<0.001 \\
\text { versus placebo }\end{array}$ & $N / R$ \\
\hline \multirow[t]{2}{*}{$N / R$} & $\begin{array}{l}\text { Change from placebo } \\
2.7 \%, P<0.001\end{array}$ & $\begin{array}{l}\text { Change from placebo } \\
2.7 \%, P<0.001\end{array}$ & $\begin{array}{l}\text { Urinary CTX } \\
-31.5 \%, P<0.001 \\
\text { versus placebo }\end{array}$ & $N / R$ \\
\hline & $N / R$ & $N / R$ & $N / R$ & $N / R$ \\
\hline \multirow[t]{2}{*}{$0.47(0.26-0.79), P=0.005$} & $N / R$ & $N / R$ & $N / R$ & $N / R$ \\
\hline & $1.5 \%$ & $-0.8 \%$ & $N / R$ & $N / R$ \\
\hline \multirow[t]{2}{*}{$0.79(0.43-1.44)$} & $8.3 \%, P<0.00 I$ versus placebo & $3.8 \%, P<0.00 I$ versus placebo & $N / R$ & $N / R$ \\
\hline & & & $N / R$ & $N / R$ \\
\hline \multirow[t]{2}{*}{$0.49(0.23-0.99)$} & $\begin{array}{l}\text { Change versus placebo } \\
6.2 \%, P<0.00 \text { I versus placebo }\end{array}$ & $\begin{array}{l}\text { Change versus placebo } \\
4.1 \%, P<0.001 \text { versus placebo }\end{array}$ & $N / R$ & $N / R$ \\
\hline & $\sim-0.8 \%^{\dagger}$ & $\sim-1.2 \%^{\dagger}$ & $N / R$ & $N / R$ \\
\hline$N / R$ & $\sim 5.0, P=$ NS versus placebo ${ }^{\dagger}$ & $\sim 1.7, P=$ NS versus placebo ${ }^{\dagger}$ & $N / R$ & $N / R$ \\
\hline$N / R$ & $\sim 8.2 \%, P<0.001$ versus placebo ${ }^{\dagger}$ & $\sim 3.2 \%, P<0.00 \mathrm{I}_{\text {versus placebo }}^{\dagger}$ & $N / R$ & $N / R$ \\
\hline$N / R$ & $\sim 7.8 \%, P=$ NS versus placebo ${ }^{\dagger}$ & $\sim 4.7 \%, P=$ NS versus placebo ${ }^{\dagger}$ & $N / R$ & $N / R$ \\
\hline \multirow[t]{2}{*}{$N / R$} & $\begin{array}{l}0.1 \%, P=\text { NS versus baseline } \\
5.0 \%, P<0.001 \text { versus baseline }\end{array}$ & $\begin{array}{l}-0.2, P=\text { NS versus baseline } \\
2.3 \%, P<0.00 I \text { versus baseline }\end{array}$ & $\begin{array}{l}\text { Urinary NTX }-21 \% \text {, } \\
\text { Urinary NTX }-74 \% \text {, } \\
P<0.00 \text { I versus } \\
\text { placebo }\end{array}$ & $\begin{array}{l}-11 \% \\
-52 \%, P<0.00 । \\
\text { versus placebo }\end{array}$ \\
\hline & I. I\%, $P<0.05$ versus baseline & $-1.2 \%, P<0.05$ versus baseline & $N / R$ & Median change $-7 \%$ \\
\hline \multirow[t]{2}{*}{$N / R$} & $5.4 \%, P<0.05$ versus baseline & $1.6 \%, P<0.05$ versus baseline & $N / R$ & Median change $-33 \%$ \\
\hline & $N / R$ & $N / R$ & $N / R$ & $N / R$ \\
\hline \multirow[t]{2}{*}{$N / R$} & $\begin{array}{l}\text { Change versus placebo } 5.9 \% \\
(95 \% \mathrm{Cl} 4.5-7.3), P<0.00 \mathrm{I}\end{array}$ & $\begin{array}{l}\text { Change versus placebo } 3.1 \% \\
(95 \% \mathrm{Cl} \mathrm{I} .8-4.5), P<0.00 \mathrm{I})\end{array}$ & $N / R$ & $N / R$ \\
\hline & $N / R$ & $N / R$ & $N / R$ & $N / R$ \\
\hline $\begin{array}{l}\text { All women = } 0.7(0.6-0.9) \text {, } \\
P=0.02\end{array}$ & $N / R$ & $N / R$ & $N / R$ & $N / R$ \\
\hline Women aged & & Change versus placebo & & \\
\hline $\begin{array}{l}\text { 70-79 years }=0.6(0.4-0.9), \\
P=0.009\end{array}$ & & $3.4 \%, P<0.001$ & & \\
\hline $\begin{array}{l}\text { Women aged } \\
\geq 80 \text { years = no significant } \\
\text { reduction }\end{array}$ & & $N / R$ & & \\
\hline
\end{tabular}


Table 2 (Continued)

\begin{tabular}{|c|c|c|c|}
\hline \multirow[t]{2}{*}{ Study } & \multirow[t]{2}{*}{ Treatments } & \multicolumn{2}{|c|}{$\begin{array}{l}\text { Fracture reduction versus placebo } \\
\text { over } 3 \text { years (RR }[95 \% \mathrm{CI}])\end{array}$} \\
\hline & & Vertebral & Nonvertebral \\
\hline Ibandronate Osteoporosis Vertebral & Placebo & & \\
\hline Fracture Trial in North America and & Ibandronate $2.5 \mathrm{mg} /$ day & $0.38(4 I-75), P=0.000 I$ & $P=\mathrm{NS}$ \\
\hline Europe (BONE) $)^{12,70}$ & $\begin{array}{l}\text { lbandronate } 20 \mathrm{mg} \text { every other day for } 12 \text { doses } \\
\text { every } 3 \text { months }\end{array}$ & $0.50(26-66), P=0.0006$ & $P=\mathrm{NS}$ \\
\hline Health Outcomes and Reduced & Placebo & & \\
\hline $\begin{array}{l}\text { Incidence with Zoledronic Acid Once } \\
\text { Yearly (HORIZON) Pivotal Fracture } \\
\text { Trial" }\end{array}$ & Zoledronic acid $5 \mathrm{mg}$ once yearly & $0.30(0.24-0.38), P<0.00 \mathrm{I}$ & $\begin{array}{l}0.75(0.64-0.87) \\
P<0.001\end{array}$ \\
\hline Health Outcomes and Reduced & Placebo & & \\
\hline Incidence with Zoledronic Acid Once & Zoledronic acid $5 \mathrm{mg}$ once yearly & $0.54(0.32-0.92), P=0.02$ & $0.73(0.55-0.98)$ \\
\hline Yearly (HORIZON) Recurrent & & & $P=0.03$ \\
\hline Fracture Trial ${ }^{59}$ & & & \\
\hline Fracture Reduction Evaluation of & Placebo & & \\
\hline Denosumab in Osteoporosis Every & Denosumab $60 \mathrm{mg} / 3$ months & $0.32(0.26-0.4 \mathrm{I}), P<0.00 \mathrm{I}$ & $0.80(0.67-0.95)$ \\
\hline 6 Months (FREEDOM) ${ }^{17}$ & & & $P=0.01$ \\
\hline Spinal Osteoporosis Therapeutic & Placebo & & \\
\hline Intervention (SOTI) $)^{15}$ & Strontium ranelate $2 \mathrm{~g} /$ day & 0.59 (0.48-0.73), $P<0.00 \mathrm{I}$ & $P=N S$ \\
\hline Treatment of Peripheral & Placebo & & \\
\hline Osteoporosis (TROPOS) ${ }^{\wedge} 16$ & Strontium ranelate $2 \mathrm{~g} /$ day & $0.6 \mathrm{I}(0.5 \mathrm{I}-0.73), P<0.00 \mathrm{I}$ & $\begin{array}{l}0.84(0.702-0.995) \\
P=0.04\end{array}$ \\
\hline
\end{tabular}

discontinuation of denosumab $30 \mathrm{mg}$ administered every 3 months, resulted in an increase in serum CTX and bone ALP that went beyond baseline levels within 12 months (Figure 3C). ${ }^{49}$ There are no published data on the antifracture efficacy of denosumab after discontinuing treatment; however, due to the rapid loss of BMD and increase in BTMs observed thus far, data on how the risk of future fracture is affected once treatment is stopped is needed to determine whether antifracture efficacy with denosumab is long lasting.

\section{Strontium ranelate}

Strontium ranelate consists of two atoms of stable strontium and an organic moiety (ranelic acid) that when taken orally exerts modest antiresorptive and anabolic effects on bone. ${ }^{15}$ In the SOTI trial extension, after 4 years of treatment with strontium ranelate, patients crossed over from active treatment to placebo for a further year. During the year patients were taking placebo, lumbar spine BMD decreased compared with patients who remained on treatment who experienced an increase in lumbar spine BMD. BTMs also changed during the year of treatment with placebo; within 3 months of moving to placebo, significant decreases in bone ALP and significant increases in serum CTX were observed. Despite changes in both lumbar spine BMD and BTMs, the difference in annual vertebral fracture incidence between patients who continued on active treatment and those who moved to placebo was nonsignificant. This was also true for the proportion of patients with new nonvertebral fractures. ${ }^{50}$

\section{Bone-forming agents}

\section{Parathyroid hormone (PTH)}

Both teriparatide (PTH 1-34) and full length PTH (1-84) are anabolic agents for bone, which stimulate osteoblastic new bone formation and hence an increase in bone mass.

Teriparatide is a recombinant form of human $\mathrm{PTH}$ (1-34). In a follow-up to the Fracture Prevention Trial, 


\begin{tabular}{|c|c|c|c|c|}
\hline \multirow[b]{2}{*}{ Hip } & \multicolumn{4}{|c|}{ Mean change from baseline over 3 years (percentage) } \\
\hline & Lumbar spine BMD & Femoral neck BMD & Serum CTX & Serum bone ALP \\
\hline & $1.3 \%$ & $-0.6 \%$ & $N / R$ & $N / R$ \\
\hline \multirow[t]{3}{*}{$N / R$} & $6.5 \%$ & $2.8 \%$ & Urinary CTX & $N / R$ \\
\hline & & & $-65.3 \%, P<0.001$ & \\
\hline & & & versus placebo & \\
\hline \multirow[t]{6}{*}{$N / R$} & $5.7 \%$ & $2.4 \%$ & Urinary CTX & $N / R$ \\
\hline & & & $-52.7 \%, P<0.001$ & \\
\hline & & & versus placebo & \\
\hline & & & Mean value at & Mean value at \\
\hline & & & 36 months & 36 months \\
\hline & & & $0.473 \mathrm{ng} / \mathrm{mL}$ & $53.43 \mathrm{ng} / \mathrm{mL}$ \\
\hline \multirow[t]{4}{*}{$0.59(0.42-0.83), P=0.002$} & Change versus placebo & Change versus placebo & Mean value at & Mean value at \\
\hline & $6.71 \%(95 \%$ Cl 5.69-7.74) & $5.06 \%(95 \% \mathrm{Cl} 4.76-5.36)$ & 36 months & 36 months \\
\hline & & & $0.205 \mathrm{ng} / \mathrm{mL}$ & $10.61 \mathrm{ng} / \mathrm{mL}$ \\
\hline & $N / R$ & $0.7 \%$ & $N / R$ & $N / R$ \\
\hline \multirow[t]{2}{*}{$P=\mathrm{NS}$} & $N / R$ & $3.6 \%, P<0.001$ versus placebo & $N / R$ & $N / R$ \\
\hline & $N / R$ & $N / R$ & $N / R$ & $N / R$ \\
\hline \multirow[t]{3}{*}{$0.60(0.37-0.97), P=0.04$} & Change versus placebo & $N / R$ & Change versus placebo & $N / R$ \\
\hline & $9.2 \%, P<0.001$ versus placebo & & $-72 \%$ & \\
\hline & $N / R$ & $N / R$ & $\sim 520 \mathrm{pmol} / \mathrm{L}^{\ddagger}$ & $\sim 1.4 \mathrm{ng} / \mathrm{mL}^{\ddagger}$ \\
\hline \multirow[t]{3}{*}{$N / R$} & Change versus placebo & Change versus placebo & $\sim 290 \mathrm{pmol} / \mathrm{L}^{\ddagger}$ & $\sim 2.35 \mathrm{ng} / \mathrm{mL}^{\ddagger}$ \\
\hline & $14.4 \%, P<0.00 \mid$ versus placebo & $8.3 \%, P<0.001$ versus placebo & & \\
\hline & $N / R$ & $N / R$ & $N / R$ & $N / R$ \\
\hline \multirow[t]{2}{*}{$P=N S$} & $N / R$ & Change versus placebo & $N / R$ & $N / R$ \\
\hline & & $8.2 \%, P<0.001$ versus placebo & & \\
\hline
\end{tabular}

Notes: All trials were 3-year, randomized, double-blind, placebo-controlled with the exception of: a Mean treatment duration was 4.2 years; ${ }^{b} \mathrm{I}-\mathrm{year}$ trial; ${ }^{\mathrm{c} 5}$-year trial;

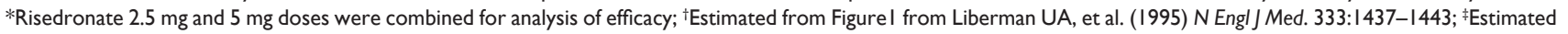
from Figure 4 from Meunier PJ, et al (2004). N Engl J Med. 350:459-468.

Abbreviations: $\mathrm{Cl}$, confidence interval; N/R, not reported; RR, risk reduction; NS, not significant; BMD, bone mineral density; CTX, serum C-telopeptide of type I collagen; ALP, alkaline phosphatase.

discontinuation of treatment resulted in a gradual reduction in BMD over 18 months, which did not fall below baseline (Figure 1D). ${ }^{51}$ This was associated with a sustained reduction in vertebral fracture risk over 18 months of follow-up.

In the Parathyroid Hormone and Alendronate (PaTH) study, postmenopausal women with osteoporosis were randomized to receive treatment with PTH (1-84) for 1 year followed by placebo for 1 year, PTH (1-84) and alendronate for 1 year followed by alendronate for 1 year or alendronate for 2 years. During the year of treatment with placebo that followed 1 year of treatment with PTH (1-84), BMD at the lumbar spine declined but did not

Table 3 Summary of patient populations and treatments examined in trials of anabolic osteoporosis treatments

\begin{tabular}{|c|c|c|c|c|}
\hline \multirow[t]{2}{*}{ Study } & \multirow[t]{2}{*}{ Patients } & \multirow{2}{*}{$\begin{array}{l}\text { Number of } \\
\text { patients }\end{array}$} & \multicolumn{2}{|l|}{ Treatments } \\
\hline & & & Active & Comparative \\
\hline Fracture Prevention Trial (FPT) ${ }^{14}$ & $\begin{array}{l}\text { PM women with } \geq I \text { moderate or } \geq 2 \text { mild } \\
\text { vertebral fractures }\end{array}$ & 1637 & $\begin{array}{l}\text { Teriparatide } 20 \mu \mathrm{g} \\
\text { Teriparatide } 40 \mu \mathrm{g}\end{array}$ & Placebo \\
\hline $\begin{array}{l}\text { Treatment of Osteoporosis with } \\
\text { Parathyroid Hormone Study (TOPS) }{ }^{71}\end{array}$ & $\begin{array}{l}\text { PM women } 45-54 \text { years with lumbar spine, } \\
\text { femoral neck or total hip BMD T score } \leq-3.0 \text { or } \\
\text { BMD T score }=-2.5 \text { and } \mathrm{I}-4 \text { vertebral fractures } \\
\text { PM women aged } \geq 55 \text { years with BMD } \\
\text { T score } \leq-2.5 \text { or BMD T score } \leq-2.0 \\
\text { and I-4 vertebral fractures }\end{array}$ & 2532 & $\begin{array}{l}\text { PTH (I-84) } \\
\text { I00 } \mu g / \text { day }\end{array}$ & Placebo \\
\hline
\end{tabular}

Note: All trials were 18-month, randomized, double-blind, placebo-controlled.

Abbreviations: PM, postmenopausal; BMD, bone mineral density; PTH, parathyroid hormone. 


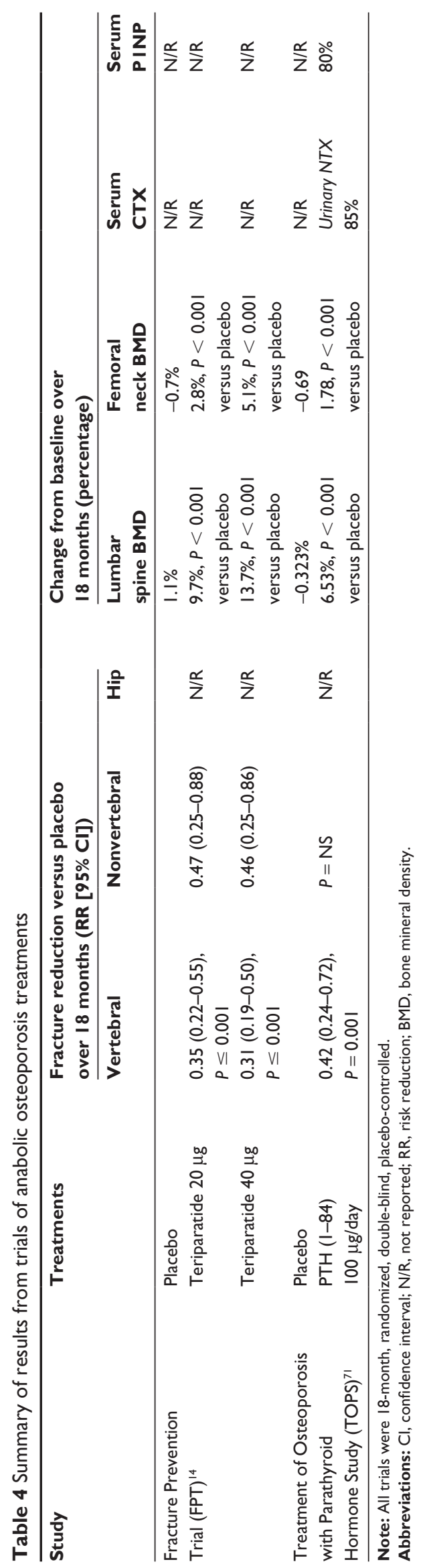

return to baseline levels. Femoral neck BMD increased and total hip BMD did not change during the same period. Both P1NP and serum CTX decreased during the year of treatment with placebo with levels of P1NP returning to baseline at the end of 12 months and levels of serum CTX returning close to baseline. The proportion of fractures did not differ between any of the treatment groups over the 2-year period of the study. ${ }^{52}$

\section{Osteoporosis treatments in clinical trials: summary}

Clinical studies of different classes of osteoporosis treatments show that whilst all approved treatments increase bone density and provide a degree of fracture protection, the effects of discontinuing treatment differ both between classes and within them. The consequences of discontinuing treatment with estrogen or raloxifene are a rapid loss of BMD and an increase in BTMs. Despite this, there is some evidence that for healthy postmenopausal women who received treatment with HRT during their early postmenopausal years, a degree of vertebral fracture protection remained for a number of years after treatment was stopped.

For bisphosphonates, studies have shown that the antifracture efficacy may continue even when treatment is discontinued. This could be explained by the fact that bisphosphonates bind tightly to bone and once bound are released slowly during the process of bone turnover, ${ }^{53}$ potentially making the bisphosphonate continuously available for some time after the patient has stopped taking the treatment. Overall, even when treatment for 3 years with alendronate and risedronate is discontinued, some antifracture efficacy remains. Decreases in BMD were gradual and did not return to baseline within 1 year of discontinuing risedronate treatment ${ }^{46}$ and 3 years of discontinuing alendronate. ${ }^{44}$ Changes in BTM upon discontinuation of treatment do differ between alendronate and risedronate. For both drugs, BTMs increased after discontinuation; however, the degree of increase and the timeframe over which the increase occurs differ between the two drugs. ${ }^{44,46}$ The clinical significance of these differences is currently unknown. What is also unclear from the available discontinuation data is which patients are likely to achieve the most comprehensive antifracture efficacy from continued treatment. Subgroup analysis of the FLEX study indicates that it is patients who remain at high risk for fracture after 5 years of treatment who benefit from continuing with treatment; however, numbers of fractures in this study were small and so the results should be interpreted with caution. ${ }^{44}$ Analysis 


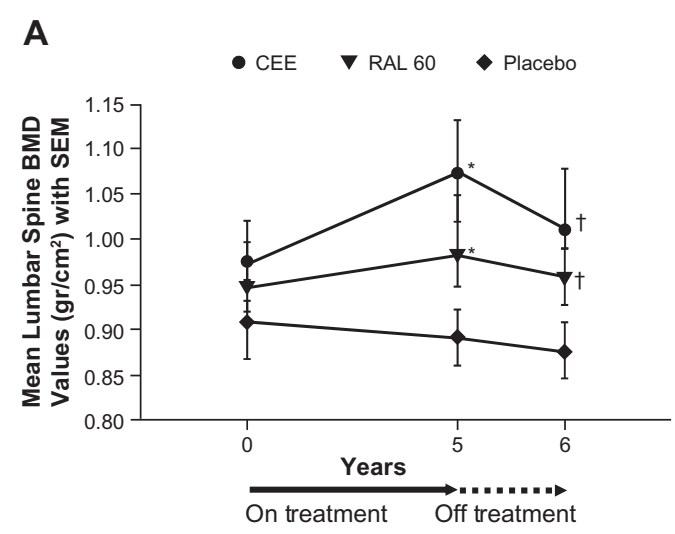

C

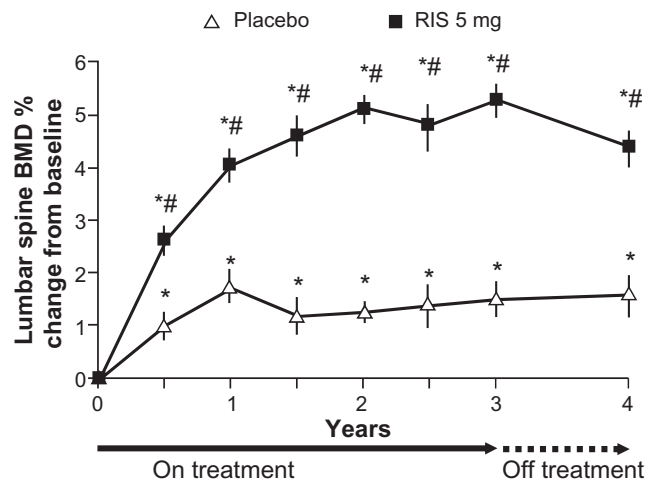

B

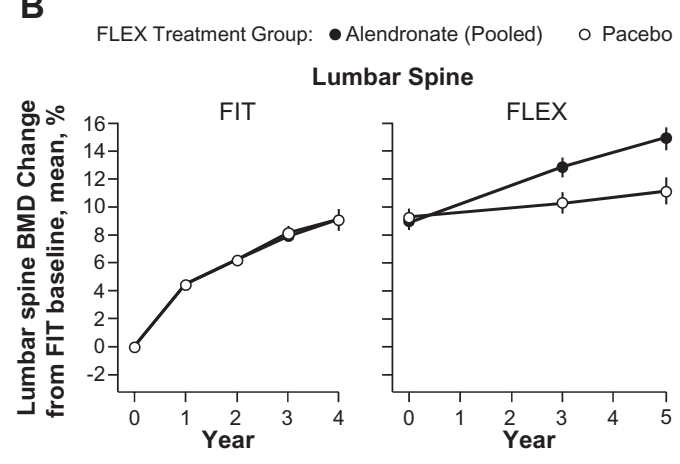

D

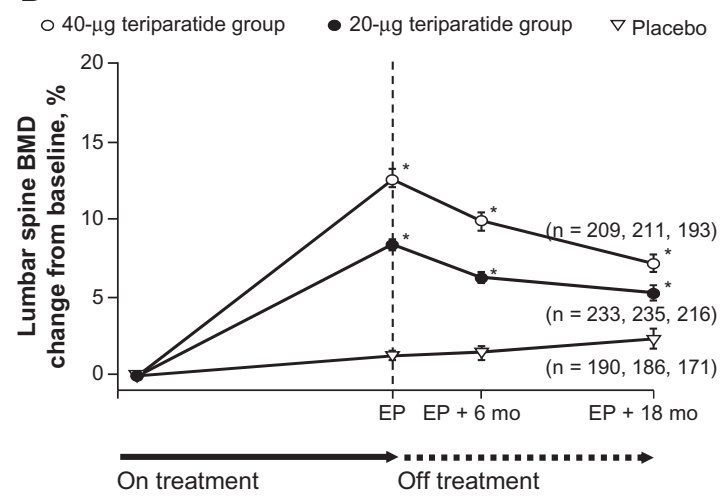

Figure I Changes in lumbar spine BMD: A) during, and after treatment with raloxifene (mean \pm SEM $\left.\left[\mathrm{g} / \mathrm{cm}^{2}\right]\right)$; ${ }^{43} \mathbf{B}$ ) during alendronate treatment in the FIT trial and alendronate or placebo treatment in the FLEX trial (mean percent change from baseline); ${ }^{44} \mathbf{C}$ ) during 3 years of blinded treatment with placebo or risedronate 5 mg daily, followed by I year of open label treatment with calcium (and vitamin D, if needed) [mean percent change from baseline]; ${ }^{46} \mathbf{D}$ ) during and after treatment with teriparatide in women who did not use any osteoporosis drugs during the 18 month follow-up period (mean percent change from baseline). ${ }^{51}$

Notes: A) $* P<0.05$ for within-group analysis (baseline versus. treatment); ${ }^{\dagger} P<0.05$ for within-group analysis (treatment versus. post-treatment); B) BMD = bone mineral density, FIT $=$ Fracture Intervention Trial, FLEX = Fracture Intervention Trial Long-term Extension. Error bars indicate $95 \%$ confidence intervals. Data are shown for the period spanning the beginning of FIT through the completion of FLEX, a total of 10 years; C) $* P<0.05$ from baseline based upon a paired t-test; ${ }^{*} P<0.05$ from placebo; D) $\mathrm{EP}=$ end point of the Fracture prevention Trial (end of teriparatide treatment), $* P<0.00 \mathrm{I}$.

of data from the HORIZON-PFT extension study will be required to determine if a similar pattern exists following treatment with zoledronic acid.

Data on the effects of discontinuing treatment with RANKL inhibitors are limited. A phase III study of denosumab showed that when treatment was halted there was a rapid decrease in lumbar spine and total hip BMD back to baseline within 12 months ${ }^{48}$ and a phase II study showed an increase in BTMs to beyond baseline levels within the same period. ${ }^{49}$ There are currently no data on whether antifracture efficacy continues when patients stop treatment with denosumab.

When treatment with strontium ranelate is stopped, BMD decreases and BTMs increase although within the first 12 months after treatment is halted, there is no reduction in antifracture efficacy. ${ }^{50}$ Halting treatment with PTH results in a gradual decline in BMD but without a loss in vertebral fracture risk reduction during the first 18 months after discontinuing treatment. ${ }^{51}$

\section{Drug holidays}

The issue of whether physicians should consider a drug holiday for patients taking osteoporosis treatments is closely related to the consequences of discontinuing versus continuing treatment over the long term. The FLEX study, as previously discussed, showed that an additional 5 years of alendronate treatment following an initial 5 years did not significantly reduce the risk of morphometric vertebral fractures or nonvertebral fractures in the overall population. ${ }^{44}$ However, in women with low femoral neck BMD, there was a significant reduction in risk of nonvertebral fractures with continued treatment. ${ }^{45}$ In addition, the results from the follow-up to the VERT studies of risedronate showed that fracture risk remained reduced 1 year after treatment was discontinued. ${ }^{46}$ These data suggest that patients may be able to take a break from treatment without incurring additional fracture risk. However, the post-hoc analysis of women with low femoral neck BMD in the FLEX study suggest that patients who may be considered to still be at high risk for fracture after 5 years of treatment should continue with treatment. 

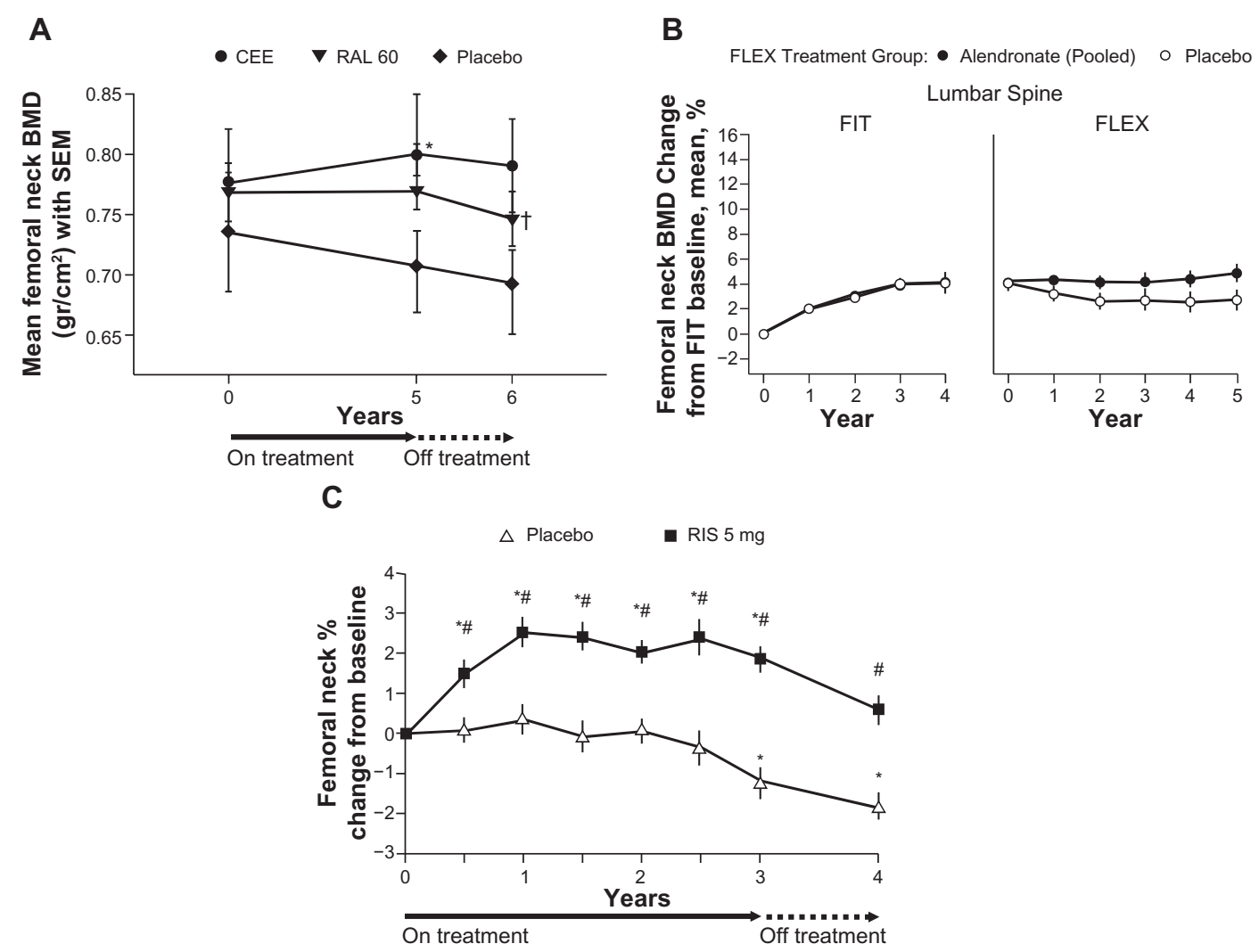

Figure 2 Changes in femoral neck BMD: A) during and after treatment with raloxifene (mean \pm SEM $\left[\mathrm{g} / \mathrm{cm}^{2}\right]$ ); ${ }^{43} \mathbf{B}$ ) during alendronate treatment in the FIT trial and alendronate or placebo treatment in the FLEX trial (mean percent change from baseline); ${ }^{44} \mathbf{C}$ ) during 3 years of blinded treatment with placebo or risedronate 5 mg daily, followed by I year of open label treatment with calcium (and vitamin D, if needed) [mean percent change from baseline]. ${ }^{46}$

Notes: A) $* P<0.05$ for within-group analysis (baseline versus treatment); ${ }^{\dagger} P<0.05$ for within-group analysis (treatment versus post-treatment); B) BMD = bone mineral density, FIT = Fracture Intervention Trial, FLEX = Fracture Intervention Trial Long-term Extension. Error bars indicate $95 \%$ confidence intervals. Data are shown for the period spanning the beginning of FIT through the completion of FLEX, a total of 10 years; $\mathbf{C}) * P<0.05$ from baseline based upon a paired t-test' ${ }^{*} P<0.05$ from placebo.

The issue of which patients may be suitable for a drug holiday, and the length of that holiday, is one that requires substantially more research on the long-term benefits versus the risks of specific treatments from well-designed, placebocontrolled trials. It is likely that only certain subgroups of low risk patients should be considered for a break in treatment with patients at high risk remaining on treatment.

Drug holidays also need to be carefully considered in light of the issues of poor treatment adherence. If patients have not adhered to treatment, then the expected gains in BMD, decreased bone turnover and ultimately, protection from fracture, are unlikely to exist. Therefore, when a patient is assessed after several years of treatment, the assumption that they have received the equivalent benefit to that observed by patients participating in clinical trials may be false. Given that studies have shown that physicians can overestimate the adherence of their patients, reassessment of the patient's risk factors for fracture is critical to ensure that discontinuing treatment is the appropriate course of action for a specific patient. Ongoing reassessment of patients who stop treatment should also be considered.

\section{Discussion}

Osteoporosis and the fragility fractures associated with the disease are an increasing problem and pose an ever-growing burden to a society with an increasing elderly population. However, there are still a number of barriers to achieving effective fracture protection for patients, despite the availability of a wide range of efficacious treatments. These include obtaining a diagnosis, being prescribed an efficacious treatment and compliance with the treatment regimen.

Optimum fracture protection for patients with osteoporosis requires that they adhere to treatment. Despite this, numerous papers report that many patients do not continue with treatment after diagnosis. ${ }^{24,25,27,29-31,54}$ Factors affecting adherence include a) a belief in the importance of taking medication for osteoporosis, ${ }^{30} \mathrm{~b}$ ) beliefs regarding medications and health in general, ${ }^{55,56} \mathrm{c}$ ) doctor and other healthcare provider 

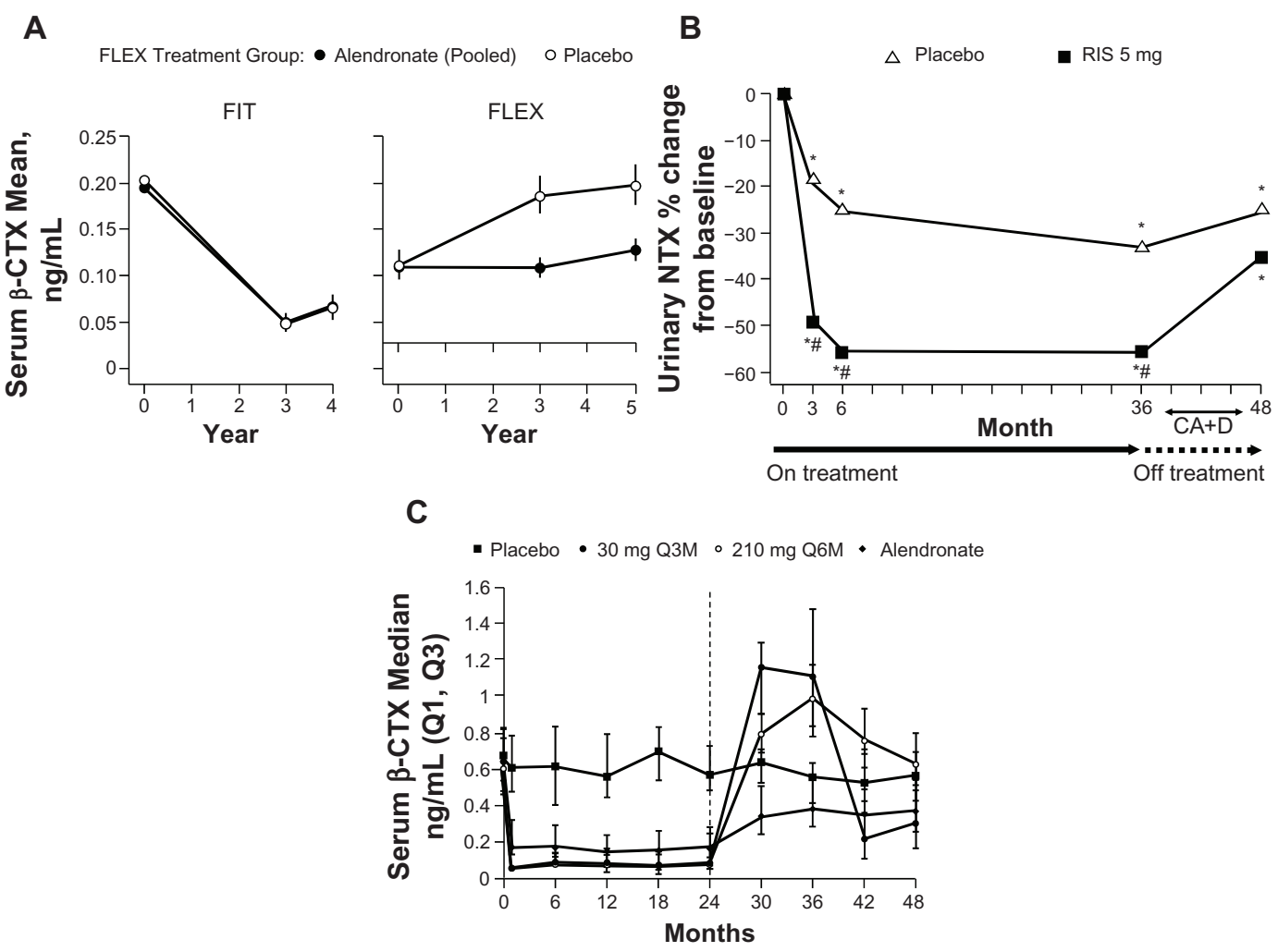

Figure 3 Changes in bone resorption markers: A) serum $\beta$-CTX during alendronate treatment in the FIT trial and alendronate or placebo treatment in the FLEX trial (mean); ${ }^{44}$ B) urinary NTX during 3 years of blinded treatment with placebo or risedronate $5 \mathrm{mg}$ daily, followed by I year of open label treatment with calcium (and vitamin $\mathrm{D}$, if needed) [median percent change from baseline], ${ }^{46} \mathbf{C}$ ) serum $\beta-C T X$ during and after treatment with denosumab (median value, ng/mL). ${ }^{49}$

Notes: A) FIT = Fracture Intervention Trial, FLEX = Fracture Intervention Trial Long-term Extension. Error bars indicate $95 \%$ confidence intervals. Data are shown for the period spanning the beginning of FIT through the completion of FLEX, a total of I0 years; B) $* P<0.05$ from baseline based upon a Signed Rank t-test, ${ }^{*} P<0.05$ from placebo; C) Group receiving $30 \mathrm{mg} \mathrm{Q3M}$ discontinued denosumab treatment at Month 24 and were retreated with $60 \mathrm{mg}$ Q6M denosumab at Month 36 . Groups receiving $210 \mathrm{mg}$ Q6M or alendronate discontinued treatment for the last 24 months. The dashed line at Month 24 indicates the time at which dosing was reallocated.

relationships ${ }^{38,55}$ and d) information exchange between healthcare professionals and patients. ${ }^{38} \mathrm{~A}$ wide variety of interventions have been studied to improve adherence. These include: monitoring a patient's BTMs and providing feedback to them based on their response to therapy, structured patient education presented face-to-face or via brochures, letters, or telephone calls, telephone patient counseling in order to address individual barriers to medication adherence and use of a weekly dose versus a monthly dose together with a patient support program. ${ }^{57}$ The authors of a systematic review of such interventions concluded that one-dimensional strategies for improving adherence were ineffective and that, as with other chronic long-term diseases, the most effective strategies were likely to be multifaceted. ${ }^{57}$ Results from several studies and a recent meta-analysis suggest that osteoporosis therapy also reduces mortality risk in women and possibly men. ${ }^{58-61}$ This reported mortality benefit should have an impact on the way osteoporosis treatment is viewed and used, and should help to encourage patients to be more compliant.
If clinicians are aware that even with interventions to improve adherence to treatment, some patients will still continue to be nonadherent, it is important that they know what happens when treatment is discontinued. Differences in the design of follow-up or discontinuation studies of individual osteoporosis treatments mean that it is not possible to make direct comparisons between different treatments. Although all the treatments discussed have shown BMD declining once treatment is discontinued, the rate of loss of bone density differs according to treatment. Markers of bone turnover have also increased once treatment has been discontinued; however, the rate at which BTMs rise also differs between treatments. Examination of the reduction in fracture risk in patients once they have stopped treatments such as alendronate, risedronate or strontium indicates that some degree of fracture risk reduction may remain; although these data are mostly uncontrolled and therefore must be interpreted with caution. Patients in these studies were taking active treatment for between 3 and 5 years prior to treatment 
being stopped and it is therefore likely that these patients had achieved and were maintaining the maximum fracture protection from each of the respective treatments when it was halted. This level of fracture protection may not be achieved in patients in the real-world as adherence studies indicate that a large number of patients discontinue treatment within the first 6 months. It is also important to examine which patient subgroups maintained their fracture protection once treatment had been discontinued. This is highlighted by the results from the FLEX trial of alendronate which showed that only patients with a low femoral neck BMD T-score after 5 years of alendronate treatment continued to benefit from an additional 5 years of treatment. The lack of increased efficacy and the potential safety concerns associated with long-term treatment have led to questions regarding whether clinicians should instigate a drug holiday for patients who have taken osteoporosis treatments, specifically bisphosphonates for 5 years or more. Although data on this topic are limited, it may be appropriate for patients who continue to be at high risk for fracture to remain on treatment and patients at low risk for fracture to cease treatment and continue to be monitored.

Overall, the consequences of not being treated or not adhering to treatment are high for patients with osteoporosis. Without effective treatment and adherence to treatment, patients will continue to be at high risk for fracture and the associated morbidity and mortality. Clinicians must ensure that their patients understand the significance of the disease, the importance of their treatment and are able to discuss with them any issues they face whilst taking a specific treatment.

\section{Conclusion}

Patients who are not diagnosed or followed-up after a fragility fracture are at high risk of experiencing another fracture in the future. Once diagnosed, patients who fail to comply with treatment for osteoporosis are known to increase their risk of future fracture regardless of the efficacy of the treatment prescribed. ${ }^{62}$ Despite the availability of a range of efficacious treatments, a lack of adherence is a well recognized issue. Failure to tackle this has consequences both for the patient, in terms of avoidable morbidity and mortality, and for healthcare providers who are required to invest more time and fund additional treatment. Given that osteoporosis is an ever-growing burden, improving adherence to treatment will require clinicians to develop multifactorial approaches to adherence and to tackle issues specific to individual patients. Additional data are required on the long-term changes in fracture risk when treatments are discontinued to help clinicians determine how to provide their patients with optimum protection from fracture.

\section{Disclosure}

J.D. Adachi, Research support and consultant: Amgen, Astra Zeneca, Eli Lilly, GlaxoSmithKline, Merck, Novartis, Nycomed, Pfizer, Procter and Gamble, Roche, Sanofi Aventis, Servier, Warner Chilcott, Wyeth.

R.G.G. Russell, Research support from Warner Chilcott Pharmaceuticals, Consultant/speaker activities Amgen, GlaxoSmithKline, Novartis, Lilly, Roche, Warner Chilcott Pharmaceuticals.

R.G. Josse, Advisory board member or consultant/ speaker activities: Amgen, GlaxoSmithKline, Novartis, Lilly, Warner Chilcott, Pfizer.

\section{References}

1. Dennison E, Mohamed MA, Cooper C. Epidemiology of osteoporosis. Rheum Dis Clin North Am. 2006;32(4):617-629.

2. Harvey N, Dennison E, Cooper C. Osteoporosis: impact on health and economics. Nat Rev Rheumatol. 2010;6(2):99-105.

3. Freedman KB, Kaplan FS, Bilker WB, Strom BL, Lowe RA. Treatment of osteoporosis: are physicians missing an opportunity? J Bone Joint Surg Am. 2000;82-A(8):1063-1070.

4. Papaioannou A, Kennedy CC, Ioannidis G, et al. The osteoporosis care gap in men with fragility fractures: the Canadian Multicentre Osteoporosis Study. Osteoporos Int. 2008;19(4):581-587.

5. Skedros JG, Holyoak JD, Pitts TC. Knowledge and opinions of orthopaedic surgeons concerning medical evaluation and treatment of patients with osteoporotic fracture. J Bone Joint Surg Am. 2006;88(1):18-24.

6. Eisman J, Clapham S, Kehoe L. Osteoporosis prevalence and levels of treatment in primary care: the Australian BoneCare Study. $J$ Bone Miner Res. 2004;19(12):1969-1975.

7. Cadarette SM, Katz JN, Brookhart MA, et al. Trends in drug prescribing for osteoporosis after hip fracture; 1995-2004. J Rheumatol. 2008;35(2): 319-326.

8. Stafford RS, Drieling RL, Hersh AL. National trends in osteoporosis visits and osteoporosis treatment; 1988-2003. Arch Intern Med. 2004; 164(14):1525-1530.

9. Ettinger B, Black DM, Mitlak BH, et al. Reduction of vertebral fracture risk in postmenopausal women with osteoporosis treated with raloxifene: results from a 3-year randomized clinical trial. Multiple Outcomes of Raloxifene Evaluation (MORE) Investigators. JAMA. 1999;282(7):637-645.

10. Black DM, Thompson DE, Bauer DC, et al. Fracture risk reduction with alendronate in women with osteoporosis: the Fracture Intervention Trial. FIT Research Group. J Clin Endocrinol Metab. 2000;85(11): 4118-4124.

11. Black DM, Delmas PD, Eastell R, et al. Once-yearly zoledronic acid for treatment of postmenopausal osteoporosis. N Engl J Med. 2007;356(18): 1809-1822.

12. Chesnut CH III, Skag A, Christiansen C, et al. Effects of oral ibandronate administered daily or intermittently on fracture risk in postmenopausal osteoporosis. J Bone Miner Res. 2004;19(8):1241-1249.

13. Harris ST, Watts NB, Genant HK, et al. Effects of risedronate treatment on vertebral and nonvertebral fractures in women with postmenopausal osteoporosis: a randomized controlled trial. Vertebral Efficacy With Risedronate Therapy (VERT) Study Group. JAMA. 1999;282(14): 1344-1352.

14. Neer RM, Arnaud CD, Zanchetta JR, et al. Effect of parathyroid hormone (1-34) on fractures and bone mineral density in postmenopausal women with osteoporosis. N Engl J Med. 2001;344(19):1434-1441.

15. Meunier PJ, Roux C, Seeman E, et al. The effects of strontium ranelate on the risk of vertebral fracture in women with postmenopausal osteoporosis. N Engl J Med. 2004;350(5):459-468. 
16. Reginster JY, Seeman E, de Vernejoul MC, et al. Strontium ranelate reduces the risk of nonvertebral fractures in postmenopausal women with osteoporosis: Treatment of Peripheral Osteoporosis (TROPOS) study. J Clin Endocrinol Metab. 2005;90(5):2816-2822.

17. Cummings SR, San MJ, McClung MR, et al. Denosumab for prevention of fractures in postmenopausal women with osteoporosis. $\mathrm{N} \mathrm{Engl}$ J Med. 2009;361(8):756-765.

18. The Writing Group for the PEPI Trial. Effects of hormone therapy on bone mineral density: results from the postmenopausal estrogen/progestin interventions (PEPI) trial. JAMA. 1996;276(17):1389-1396.

19. Rabenda V, Mertens R, Fabri V, et al. Adherence to bisphosphonates therapy and hip fracture risk in osteoporotic women. Osteoporos Int. 2008;19(6):811-818.

20. Downey TW, Foltz SH, Boccuzzi SJ, Omar MA, Kahler KH. Adherence and persistence associated with the pharmacologic treatment of osteoporosis in a managed care setting. South Med J. 2006;99(6):570-575.

21. Weycker D, Macarios D, Edelsberg J, Oster G. Compliance with drug therapy for postmenopausal osteoporosis. Osteoporos Int. 2006;17(11): 1645-1652.

22. Huybrechts KF, Ishak KJ, Caro JJ. Assessment of compliance with osteoporosis treatment and its consequences in a managed care population. Bone. 2006;38(6):922-928.

23. Jones TJ, Petrella RJ, Crilly R. Determinants of persistence with weekly bisphosphonates in patients with osteoporosis. J Rheumatol. 2008;35(9): 1865-1873.

24. Penning-van Beest FJ, Goettsch WG, Erkens JA, Herings RM. Determinants of persistence with bisphosphonates: a study in women with postmenopausal osteoporosis. Clin Ther. 2006;28(2):236-242.

25. Siris ES, Harris ST, Rosen CJ, et al. Adherence to bisphosphonate therapy and fracture rates in osteoporotic women: relationship to vertebral and nonvertebral fractures from 2 US claims databases. Mayo Clin Proc. 2006;81(8):1013-1022.

26. Cramer JA, Gold DT, Silverman SL, Lewiecki EM. A systematic review of persistence and compliance with bisphosphonates for osteoporosis Osteoporos Int. 2007;18(8):1023-1031.

27. Imaz I, Zegarra P, Gonzalez-Enriquez J, Rubio B, Alcazar R, Amate JM. Poor bisphosphonate adherence for treatment of osteoporosis increases fracture risk: systematic review and meta-analysis. Osteoporos Int 2010;21(11):1943-1951

28. Roughead EE, Ramsay E, Priess K, Barratt J, Ryan P, Gilbert AL. Medication adherence, first episode duration, overall duration and time without therapy: the example of bisphosphonates. Pharmacoepidemiol Drug Saf. 2009;18(1):69-75.

29. Copher R, Buzinec P, Zarotsky V, Kazis L, Iqbal SU, Macarios D. Physician perception of patient adherence compared to patient adherence of osteoporosis medications from pharmacy claims. Curr Med Res Opin. 2010;26(4):777-785.

30. Kamatari M, Koto S, Ozawa N, et al. Factors affecting long-term compliance of osteoporotic patients with bisphosphonate treatment and QOL assessment in actual practice: alendronate and risedronate. J Bone Miner Metab. 2007;25(5):302-309.

31. Aki S, Eskiyurt N, Akarirmak U, et al. Gastrointestinal side effect profile due to the use of alendronate in the treatment of osteoporosis. Yonsei Med J. 2003;44(6):961-967.

32. Kendler D, Kung AW, Fuleihan G, et al. Patients with osteoporosis prefer once weekly to once daily dosing with alendronate. Maturitas. 2004;48(3):243-251.

33. Ringe JD, Moller G. Differences in persistence, safety and efficacy of generic and original branded once weekly bisphosphonates in patients with postmenopausal osteoporosis: 1-year results of a retrospective patient chart review analysis. Rheumatol Int. 2009;3(2):213-221.

34. Cotte FE, Fardellone P, Mercier F, Gaudin AF, Roux C. Adherence to monthly and weekly oral bisphosphonates in women with osteoporosis. Osteoporos Int. 2010;21(1):145-155.

35. Recker RR, Gallagher R, MacCosbe PE. Effect of dosing frequency on bisphosphonate medication adherence in a large longitudinal cohort of women. Mayo Clin Proc. 2005;80(7):856-861.
36. Fraenkel L, Gulanski B, Wittink D. Patient treatment preferences for osteoporosis. Arthritis Rheum. 2006;55(5):729-735.

37. Grima DT, Papaioannou A, Airia P, Ioannidis G, Adachi JD. Adverse events, bone mineral density and discontinuation associated with generic alendronate among postmenopausal women previously tolerant of brand alendronate: a retrospective cohort study. BMC Musculoskelet Disord. 2010;11:68.

38. Clowes JA, Peel NF, Eastell R. The impact of monitoring on adherence and persistence with antiresorptive treatment for postmenopausal osteoporosis: a randomized controlled trial. J Clin Endocrinol Metab. 2004;89(3):1117-1123.

39. Penning-van Beest FJ, Erkens JA, Olson M, Herings RM. Loss of treatment benefit due to low compliance with bisphosphonate therapy. Osteoporos Int. 2008;19(4):511-517.

40. Danese MD, Badamgarav E, Bauer DC. Effect of adherence on lifetime fractures in osteoporotic women treated with daily and weekly bisphosphonates. J Bone Miner Res. 2009;24(11):1819-1826.

41. Gallagher JC, Rapuri PB, Haynatzki G, Detter JR. Effect of discontinuation of estrogen, calcitriol, and the combination of both on bone density and bone markers. J Clin Endocrinol Metab. 2002;87(11):4914- 4923.

42. Bagger YZ, Tanko LB, Alexandersen P, et al. Two to three years of hormone replacement treatment in healthy women have long-term preventive effects on bone mass and osteoporotic fractures: the PERF study. Bone. 2004;34(4):728-735.

43. Neele SJ, Evertz R, De Valk-De RG, Roos JC, Netelenbos JC. Effect of 1 year of discontinuation of raloxifene or estrogen therapy on bone mineral density after 5 years of treatment in healthy postmenopausal women. Bone. 2002;30(4):599-603.

44. Black DM, Schwartz AV, Ensrud KE, et al. Effects of continuing or stopping alendronate after 5 years of treatment: the Fracture Intervention Trial Long-term Extension (FLEX): a randomized trial. JAMA. 2006; 296(24):2927-2938.

45. Schwartz AV, Bauer DC, Cummings SR, et al. Efficacy of continued alendronate for fractures in women with and without prevalent vertebral fracture: The FLEX trial. J Bone Miner Res. 2010;25(5):976-982.

46. Watts NB, Chines A, Olszynski WP, et al. Fracture risk remains reduced one year after discontinuation of risedronate. Osteoporos Int. 2008; 19(3):365-372.

47. Devogelaer JP, Brown JP, Burckhardt P, et al. Zoledronic acid efficacy and safety over five years in postmenopausal osteoporosis. Osteoporos Int. 2007;18(9):1211-1218.

48. Popat V. Denosumab efficacy FDA analysis. Proceedings of the August 13, 2009 Meeting of the Reproductive Health Drugs Advisory Committee. Gaithersburg, Maryland; 2009.

49. Miller PD, Bolognese MA, Lewiecki EM, et al. Effect of denosumab on bone density and turnover in postmenopausal women with low bone mass after long-term continued, discontinued, and restarting of therapy: a randomized blinded phase 2 clinical trial. Bone. 2008;43(2):222-229.

50. Kendler DL, Adachi JD, Josse RG, Slosman DO. Monitoring strontium ranelate therapy in patients with osteoporosis. Osteoporos Int. 2009; 20(7):1101-1106.

51. Lindsay R, Scheele WH, Neer R, et al. Sustained vertebral fracture risk reduction after withdrawal of teriparatide in postmenopausal women with osteoporosis. Arch Intern Med. 2004;164(18):2024-2030.

52. Black DM, Bilezikian JP, Ensrud KE, et al. One year of alendronate after one year of parathyroid hormone (1-84) for osteoporosis. $N$ Engl J Med. 2005;353(6):555-565.

53. Russell RG, Watts NB, Ebetino FH, Rogers MJ. Mechanisms of action of bisphosphonates: similarities and differences and their potential influence on clinical efficacy. Osteoporos Int. 2008;19(6):733-759.

54. Roughead EE, Ramsay E, Priess K, Barratt J, Ryan P, Gilbert AL. Medication adherence, first episode duration, overall duration and time without therapy: the example of bisphosphonates. Pharmacoepidemiol Drug Saf. 2009;18(1):69-75.

55. Lau E, Papaioannou A, Dolovich L, et al. Patients' adherence to osteoporosis therapy: exploring the perceptions of postmenopausal women. Can Fam Physician. 2008;54(3):394-402. 
56. Simpson SH, Eurich DT, Majumdar SR, et al. A meta-analysis of the association between adherence to drug therapy and mortality. BMJ. 2006;333(7557):15

57. Gleeson T, Iversen MD, Avorn J, et al. Interventions to improve adherence and persistence with osteoporosis medications: a systematic literature review. Osteoporos Int. 2009;20(12):2127-2134.

58. Center JR, Bliuc D, Nguyen ND, Nguyen TV, Eisman JA. Osteoporosis medication and reduced mortality risk in elderly women and men. J Clin Endocrinol Metab. 2011;96(4):1006-1014.

59. Lyles KW, Colon-Emeric CS, Magaziner JS, et al. Zoledronic acid in reducing clinical fracture and mortality after hip fracture. $N$ Engl J Med. 2007;357(18):1799-1809.

60. Bolland MJ, Grey AB, Gamble GD, Reid IR. Effect of osteoporosis treatment on mortality: a meta-analysis. J Clin Endocrinol Metab. 2010;95(3):1174-1181.

61. Colon-Emeric CS, Mesenbrink P, Lyles KW, et al. Potential mediators of the mortality reduction with zoledronic acid after hip fracture. $J$ Bone Miner Res. 2010;25(1):91-97.

62. Siris ES, Selby PL, Saag KG, Borgstrom F, Herings RM, Silverman SL. Impact of osteoporosis treatment adherence on fracture rates in North America and Europe. Am J Med. 2009;122(2 Suppl):S3-S13.

63. Liberman UA, Weiss SR, Broll J, et al. Effect of oral alendronate on bone mineral density and the incidence of fractures in postmenopausal osteoporosis. The Alendronate Phase III Osteoporosis Treatment Study Group. N Engl J Med. 1995;333(22):1437-1443.

64. Pols HA, Felsenberg D, Hanley DA, et al. Multinational, placebocontrolled, randomized trial of the effects of alendronate on bone density and fracture risk in postmenopausal women with low bone mass: results of the FOSIT study. Fosamax International Trial Study Group. Osteoporos Int. 1999;9(5):461-468.
65. Reginster J, Minne HW, Sorensen OH, et al. Randomized trial of the effects of risedronate on vertebral fractures in women with established postmenopausal osteoporosis. Vertebral Efficacy with Risedronate Therapy (VERT) Study Group. Osteoporos Int. 2000;11(1):83-91.

66. McClung MR, Geusens P, Miller PD, et al. Effect of risedronate on the risk of hip fracture in elderly women. Hip Intervention Program Study Group. N Engl J Med. 2001;344(5):333-340.

67. Cummings SR, Black DM, Thompson DE, et al. Effect of alendronate on risk of fracture in women with low bone density but without vertebral fractures: results from the Fracture Intervention Trial. JAMA. 1998; 280(24):2077-2082.

68. Black DM, Cummings SR, Karpf DB, et al. Randomised trial of effect of alendronate on risk of fracture in women with existing vertebral fractures. Fracture Intervention Trial Research Group. Lancet. 1996;348(9041):1535-1541.

69. Reginster J, Minne HW, Sorensen OH, et al. Randomized trial of the effects of risedronate on vertebral fractures in women with established postmenopausal osteoporosis. Vertebral Efficacy with Risedronate Therapy (VERT) Study Group. Osteoporos Int. 2000;11(1):83-91.

70. Delmas PD, Recker RR, Chesnut CH III, et al. Daily and intermittent oral ibandronate normalize bone turnover and provide significant reduction in vertebral fracture risk: results from the BONE study. Osteoporos Int. 2004;15(10):792-798.

71. Greenspan SL, Bone HG, Ettinger MP, et al. Effect of recombinant human parathyroid hormone (1-84) on vertebral fracture and bone mineral density in postmenopausal women with osteoporosis: a randomized trial. Ann Intern Med. 2007;146(5):326-339.
Therapeutics and Clinical Risk Management

\section{Publish your work in this journal}

Therapeutics and Clinical Risk Management is an international, peerreviewed journal of clinical therapeutics and risk management, focusing on concise rapid reporting of clinical studies in all therapeutic areas, outcomes, safety, and programs for the effective, safe, and sustained use of medicines. This journal is indexed on PubMed Central, CAS,

\section{Dovepress}

EMBase, Scopus and the Elsevier Bibliographic databases. The manuscript management system is completely online and includes a very quick and fair peer-review system, which is all easy to use. Visit http://www.dovepress.com/testimonials.php to read real quotes from published authors. 